\title{
A Rapid Review of Prescribing Education Interventions
}

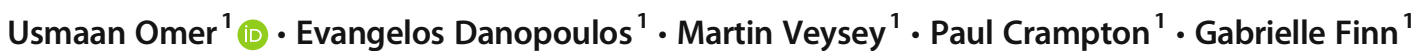

Accepted: 15 October 2020 / Published online: 16 November 2020

(C) The Author(s) 2020

\begin{abstract}
Introduction Many studies conducted on the causes and nature of prescribing errors have highlighted the inadequacy of teaching and training of prescribers. Subsequently, a rapid review was undertaken to update on the nature and effectiveness of educational interventions aimed at improving the prescribing skills and competencies.

Methods Twenty-two studies taking place between 2009 and 2019 were identified across nine databases.

Results and Discussion This review reinforced the importance of the WHO Guide to Good Prescribing to prescribing curriculum design as well as the effectiveness of small group teaching. However, it also highlighted the lack of innovation in prescribing education and lack of longitudinal follow-up regarding the effectiveness of prescribing education interventions.
\end{abstract}

Keywords Prescribing education $\cdot$ Medical students $\cdot$ Non-medical prescribers: curriculum design $\cdot$ WHO Guide to Good Prescribing

\section{Introduction}

Over time, deficiencies in prescribing education, such as a lack of practical prescribing training, a lack of linking theory to practice and the affordance of little attention towards generic prescribing skills, have led to the increasing emergence of prescribing errors [1]. A prescribing error is defined: "a clinically meaningful prescribing error occurring when... there is an unintentional significant reduction in the probability of treatment being timely and effective or increase in the risk of harm when compared with generally accepted practice" [2]. Errors in the prescription of medicines are currently one of the biggest dilemmas facing medicine and healthcare. Numerous studies have been conducted based upon prescribing errors and their impact on patient safety [3-5]. Adverse drug effects (ADEs) are found to be one of the main causes of injury to hospitalised patients [6], with over half of all prescribing errors considered as potentially harmful to patients, and $7.3 \%$ of these errors leading to life-threatening consequences [7].

Usmaan Omer

hyuo1@hyms.ac.uk

1 Health Professions Education Unit, Hull York Medical School, University of York, York YO10 5DD, UK
Previously, only doctors and dentists held the legal authority to prescribe prescription-only medicines; however, this situation recently began to change globally, with either pharmacists or nurses or both obtaining the authority to prescribe independently [8]. The United Kingdom (UK) provides the most extensive rights to pharmacists and nurses, where doctors and dentists are known as medical prescribers (MPs) and other healthcare professionals who prescribe are known as non-medical prescribers (NMPs) [9]. The rationale of this development was to provide patients with quicker access to medicines. Not only would this decrease a very heavy workload within general practice but would also widen the use of the skills of pharmacists and nurses [10]. A small number of studies exploring the effectiveness of NMP prescribing have been encouraging, demonstrating that they are making clinically appropriate prescribing decisions $[10,11]$. Baqir et al. found that pharmacist prescribers demonstrated an error rate of $0.3 \%$; however, they advocate for further, larger scale research to be conducted on the prescribing practices of NMPs to obtain a clearer picture of the nature of errors NMPs can be prone to [12]. Cope et al. have also called for more research to investigate how NMPs are trained to prescribe safely and effectively [8].

Prescribing is overall a very complicated task requiring the amalgamation of knowledge of medicines, diagnostic and communication skills, an in-depth understanding of principles underpinning clinical pharmacology and an appreciation of 
risk and uncertainty [13]. Dornan et al. conducted research to determine the causes of prescription errors. They interviewed mainly recently graduated doctors and found that out of skillbased, rule-based and knowledge-based mistakes, rule-based mistakes were the main cause of prescribing errors. They reported that this suggests a lack in the ability of junior doctors to correctly apply the knowledge acquired in undergraduate education. This was supported by a consensus that students felt there was a lack of modules preparing them for the transition from theory to practice and current pharmacology education was not beneficial enough with regard to prescribing. It was concluded that rule-based mistakes were most likely to go unnoticed and inflict harm towards the patient [1].

Nazar et al. [14] built upon the research conducted by Dornan et al. [1] to delve further into the causes of prescribing errors. Their research implied that a lack of knowledge is not solely responsible for prescribing errors. They found that methods of teaching as well as the environment of prescribing also contribute toward prescribing errors. Audit Scotland questioned the adequacy of undergraduate medical education in preparing new doctors for rational and safe prescribing [15].

Previously, a systematic review was conducted by Kamarudin et al., examining previous work on educational interventions designed to enhance the prescribing competency of both medical and non-medical prescribers [16]. However, Kamarudin et al., as well as other systematic reviews on prescribing education interventions [17, 18], have only investigated the quantitatively measured effectiveness of interventions and omitted reviewing studies which qualitatively investigate the views and perspectives of students on the various interventions.

Given that previous literature reviews have omitted qualitative studies on prescribing education interventions, coupled with the advancement of the nature of educational interventions across the medical education continuum and the time elapsed since a previous review in this area, our aim was to perform a rapid systematic review to provide an update on the scope, nature and effectiveness of educational interventions aimed at developing the prescribing skills and competencies of medical and non-medical prescribers and investigate the views and perspectives of the students regarding different prescribing educational interventions.

\section{Methods}

\section{Design}

Given that previous literature reviews evaluating prescribing education interventions had been conducted, the aim was to investigate whether and to what extent the nature of these educational interventions had evolved in the last 10 years; therefore, a rapid review was deemed most appropriate. A rapid review is defined as a form of evidence synthesis that provides more timely information for decision-making as compared to a traditional systematic review. In addition, rapid reviews have been the preferred form of evidence synthesis for reviews aiming to serve as an update on previous reviews [19]. In addition, due to the heterogeneity of the studies and the inclusion of both qualitative and quantitative studies, the data was synthesised using a narrative approach [20].

\section{Search Strategy}

The focus was towards identifying studies where an educational intervention was implemented in a curriculum to improve the prescribing skills of medical and/or non-medical prescribing students. Papers were screened from nine different databases, including MEDLINE, EMBASE, PsycINFO, Scopus, Academic Search Premier, CINAHL Complete, Cochrane Library, NIH PubMed and Google Scholar.

A search strategy was developed with the aid of a librarian from the University of York Library. The search terms entered into these databases were as follows:

\begin{tabular}{|c|c|c|}
\hline & Category & Keywords \\
\hline AND & Prescribing & Prescribing OR Prescription* OR Prescriber* \\
\hline AND & Education & Education OR Curriculum OR Training \\
\hline \multirow[t]{2}{*}{ AND } & Intervention & Intervention* OR Innovation* OR Approach* \\
\hline & Outcome & $\begin{array}{l}\text { View* OR Perspective* OR Result* OR } \\
\text { Effectiveness }\end{array}$ \\
\hline AND & Population & $\begin{array}{l}\text { Medical Student* OR Undergraduate OR } \\
\text { Postgraduate OR Non-Medical Prescriber* }\end{array}$ \\
\hline
\end{tabular}

Search terms and strategy PROSPERO registration: CRD42019145576, Available from: https://www.crd.york. ac.uk/prospero/display_record.php?ID=CRD42019145576

\section{Study Selection}

The inclusion criteria were if they were published in English, were full-text journal papers and evaluated an implemented educational intervention related to prescribing. Both qualitative and quantitative studies of any design taking place in medical schools and/or non-medical prescribing programmes were included, whether the intervention was evaluated through assessments or through qualitative student perspectives. However, they had to have taken place between the years 2009 and 2019. Papers were excluded if the educational interventions were not related to prescribing, and were systematic reviews, meeting reports, letters, opinion pieces or studies involving qualified doctors. The screening process took place in compliance with the PRISMA guidelines [21].

The titles and abstracts of the papers were reviewed by two authors to assess relevance of studies. Both authors held discussions regarding which papers should be included for full- 
text screening and an agreement was reached in a timely manner. Both authors also conducted full-text screening and, after agreeing upon $95 \%$ of the papers, selected them for data extraction.

\section{Data Extraction and Quality Appraisal}

Initially, a small number of papers underwent dual data extraction by both Usmaan Omer and Evangelos Danopolous as recommended by Waffenschmidt et al. [22] based on study design, location, study aims, type and success of educational intervention, level of innovation and specific areas of prescribing targeted by intervention. The quality of each study was assessed using the Best Evidence Medical Education (BEME) scale [23]. As both authors agreed on the data extracted, data extraction of the remaining papers was conducted by UO and ED alone.

\section{Results}

\section{Number of Studies}

Overall, a total of 1137 papers were identified across all nine databases. Following the removal of duplicates, 696 papers remained, of which 634 were excluded for reasons including having no relevance to prescribing, studies not including medical and/or non-medical prescribing students as study cohorts or studies being conducted before 2009. After consultation between the two authors, it was agreed that 58 papers should be included for full-text screening. Following the process of full-text screening, 22 papers were included for the review. (PRISMA diagram included as Appendix)

\section{Study Characteristics}

Of the 22 studies selected for the review, eight were randomised or non-randomised controlled trials, six before-and-after studies, five mixed-methods studies, two qualitative studies and one cross-sectional survey study (Tables 1, 2, 3, 4, and 5).

\section{Types of Educational Interventions}

\section{Teaching and Mentoring from Healthcare Professionals Other than Faculty Members}

Four case-based educational interventions included teaching and mentoring from qualified healthcare professionals other than faculty lecturers [24-27]. Two studies followed a group learning format using case-based scenarios [24, 25], one study used experiential learning through observations of real-life prescribing situations [27] and one study implemented a mentoring scheme between learner and expert [26].
Newby et al.'s study [24] included pharmacist-led tutorials using common case scenarios seen by junior doctors, and, similarly, Gibson and colleagues used clinical case scenarios in tutorials led by junior doctors, but these were discussed in small groups of students, who devised a clinical management plan for the patient in the clinical scenario. Tittle et al.'s study [27] used small-group tutorials with students shadowing pharmacists in clinical practice, where topics such as prescribing for acute medical emergencies, taking patient drug histories, discharge prescriptions and therapeutic drug monitoring were covered. Bowskill et al. [26] implemented a mentoring scheme in the NMP programme at Nottingham, where students were allocated an alumnus of the programme who would act as their prescribing mentor, aiding them in effectively integrating prescribing skills learnt during the programme into their area of clinical expertise.

The studies used different methods to evaluate the outcomes of their studies. Newby et al. [24] employed mixed methods to evaluate the benefits of these sessions, where students undertook a prescribing exercise and a prescribing confidence questionnaire before and after the implementation of the intervention alongside focus groups where selected students discussed the benefits and potential drawbacks of the tutorials. Post-intervention scores were significantly higher, and both the focus groups' and questionnaires' data indicated that the tutorials had improved prescribing confidence in students. Gibson et al. [25] also used end-of-session questionnaires but observed student examination performance as indicators of success. The results of the questionnaires showed that most students rated the tutorials as 'excellent', greatly enhancing their prescribing confidence, knowledge and skills with the role of the junior doctor as the teacher being well received. Both Tittle et al. [27] and Bowskill et al. [26] evaluated outcomes qualitatively through focus groups, semistructured interviews and surveys. Tittle et al.'s [27] focus group results demonstrated positive perceptions for the intervention; the role of the clinical pharmacist as the teacher and the positive effect of the intervention on their prescribing confidence were recorded. However, Bowskill et al. [26] found that although students praised the scheme for helping contextualisation of prescribing into their specific area of practice, they felt that adequate support was already provided from colleagues and tutors.

\section{Interventions Designed Using and Featuring the WHO Guide to Good Prescribing}

Six case-based interventions were conducted through exposing students to treatment-setting standards from the World Health Organization (WHO) Guide to Good Prescribing (GGP) to varying [28-33]. Two studies used a combination of didactic lectures and subsequent 


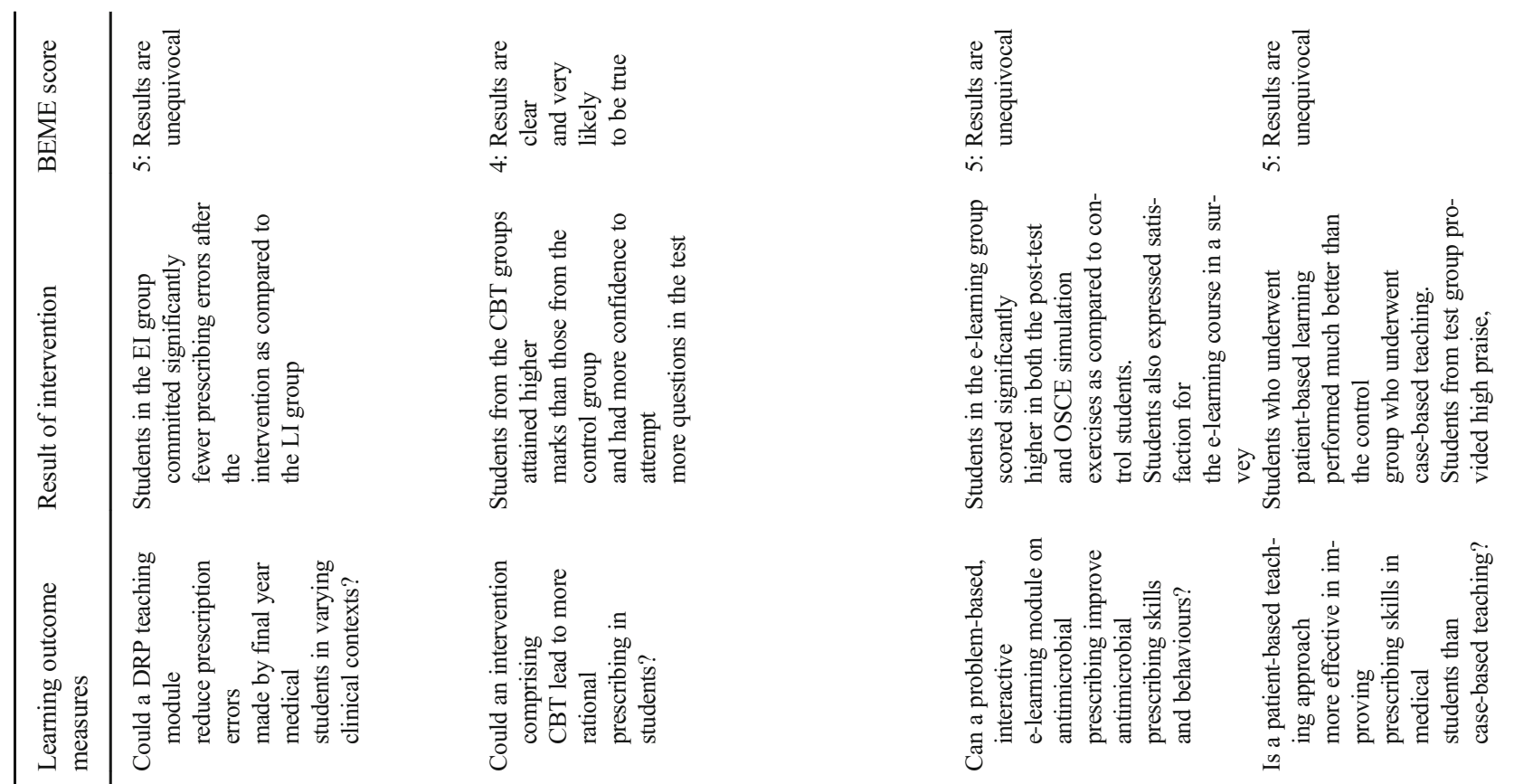

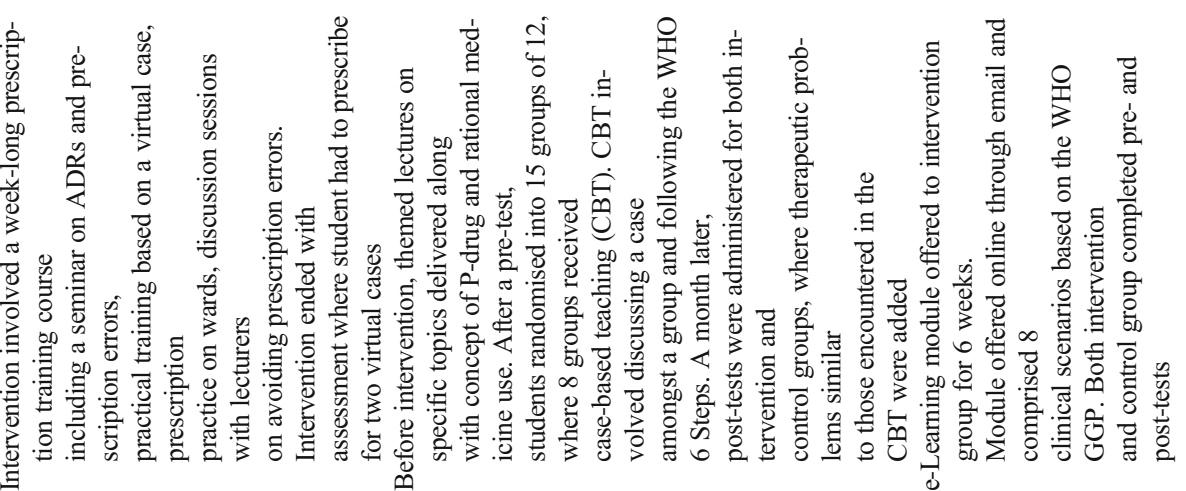
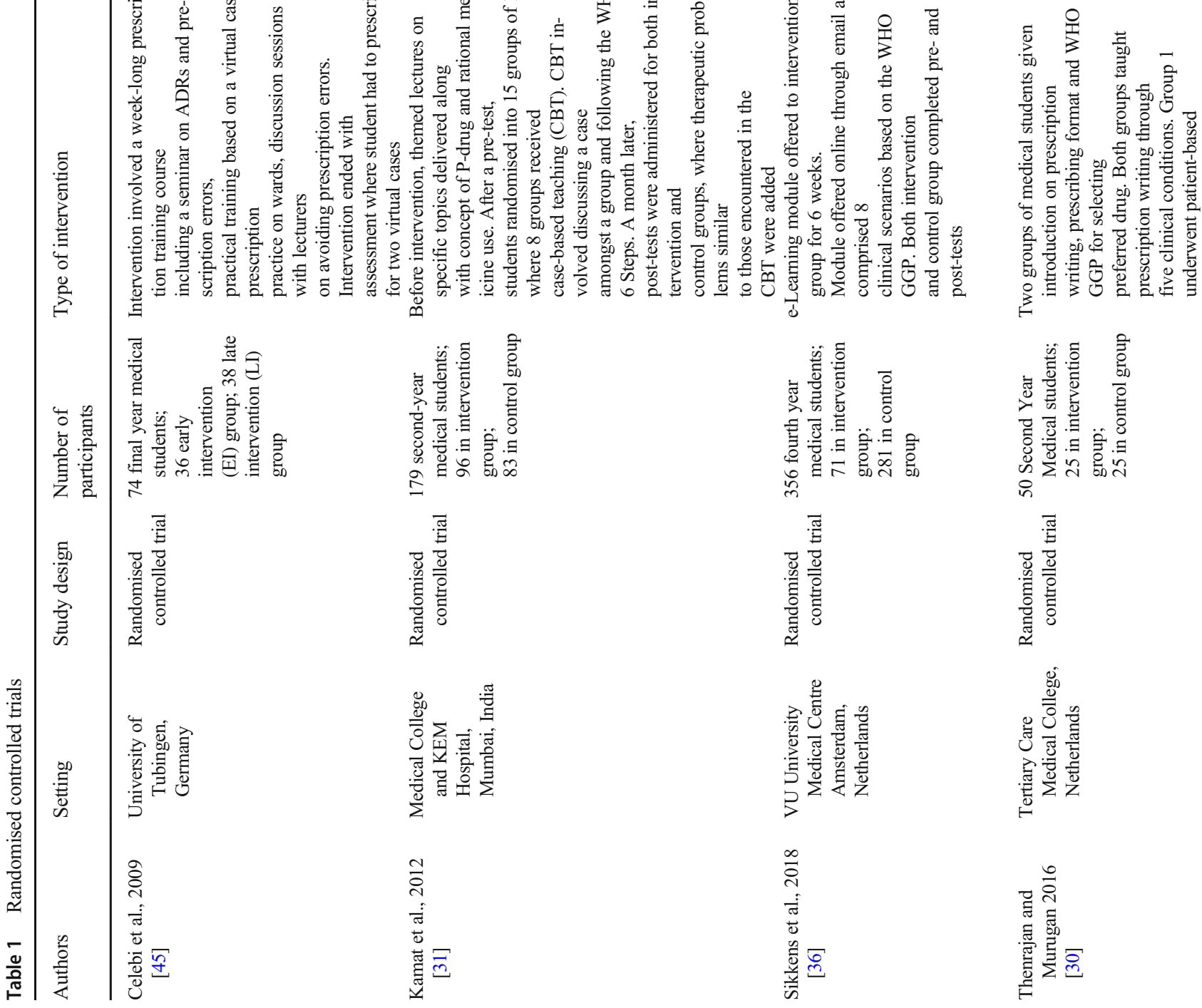

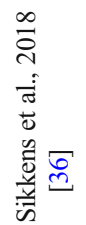

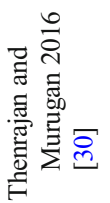




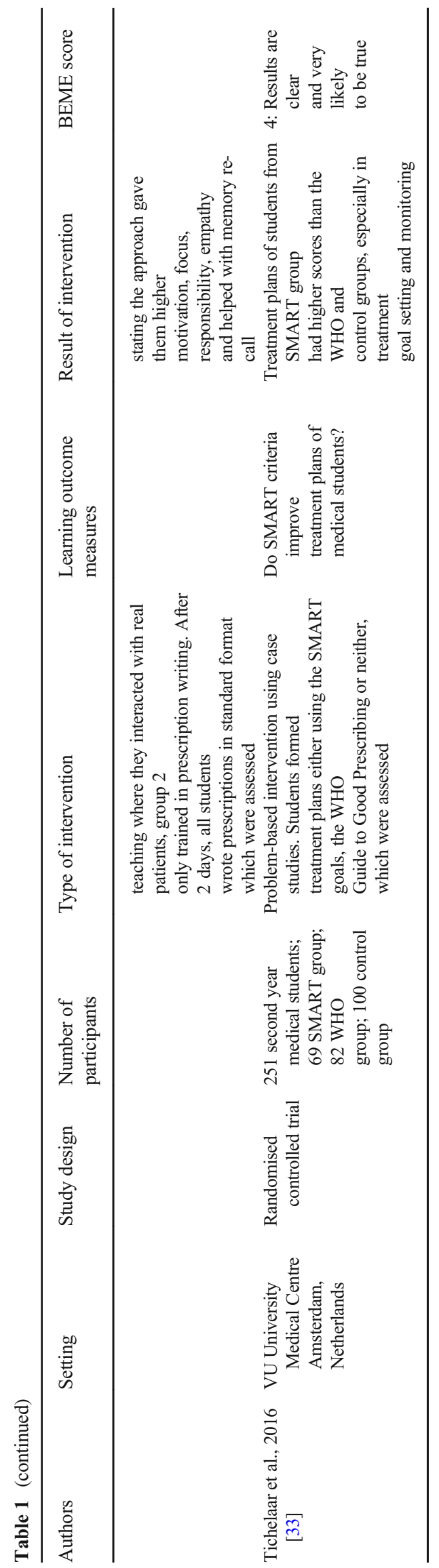

prescription-writing for specific paper case scenarios [28, 31], two studies implemented an individualised instruction approach where students were provided with the WHO GGP to use individually for creating treatment plans [32, 33], one study used an experiential approach where students learned through observing real-life patients [30] and one study implemented the WHO GGP across an entire curriculum and in a variety of teaching formats [29].

Keisjers et al. [29] made extensive use of the WHO GGP through incorporating it into a whole medical curriculum, where all pharmacology and pharmacotherapy modules were modelled according to the learning goals of the WHO GGP, and the guide was heavily featured during whole-group lectures, small-group tutorials and practical sessions. Kamat et al. [31] themed prior lectures and case-based tutorials (CBT) involving treatment of varying conditions such as diabetes mellitus, peptic ulcers and constipation on the six steps of the WHO GGP. Raghu et al. [28] recruited 117 second-year medical students and asked them to compile prescriptions for three case scenarios. After delivering rational prescribing sessions and subsequently asking for the prescriptions to be rewritten, they assessed and provided feedback to the students according to the WHO GGP standards. Both Krishnaiah et al. and Tichelaar et al. $[32,33]$ required students to use the WHO GGP as an aid in compiling treatment plans for hypothetical case scenarios; however, the purpose of Tichelaar et al.'s study [33] was to compare the impact of the WHO GGP to the 'SMART' criteria of goal setting on treatment planning. Thenrajan et al.'s study [30] used a test and a control group, both of whom were exposed to the WHO GGP guidelines of selecting the preferred drug following a clinical diagnosis. After receiving five clinical scenarios, the test group underwent patient-based teaching where they would see real patients suffering from the same conditions seen in the clinical scenarios, whereas the control group underwent further prescription-writing training.

Outcomes by most studies were assessed through scoring the treatment plans and prescriptions written by students following the intervention. Both Raghu et al. and Krishnaiah et al. [28, 32] found student treatment plans to score higher post-intervention and compared to control groups. However, Tichelaar et al. [33] found the treatment plans of students using the SMART criteria to score higher than those who used the WHO GGP. Keisjers et al. [29] examined the impact of their curricular intervention through a formative standardised assessment testing basic pharmacological knowledge (testing factual knowledge), applied pharmacological knowledge (solving clinical scenarios) and pharmacotherapy skills as well as prescription-writing. The results demonstrated that both fourth- and sixth-year students receiving the WHO GGP intervention significantly outscored their control group peers. 


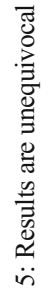

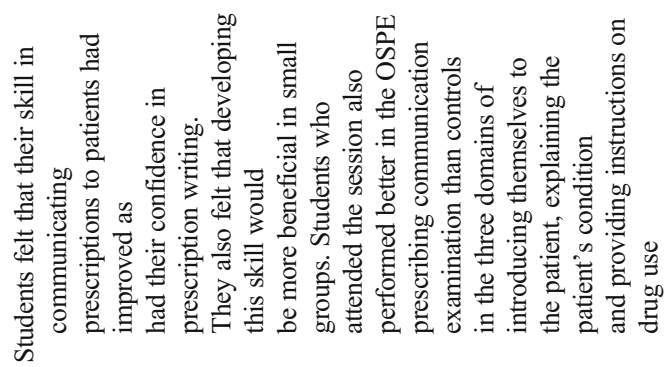

च을

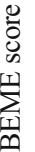

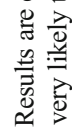

$\ddot{\nabla}$

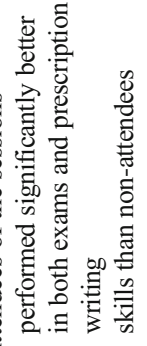

.

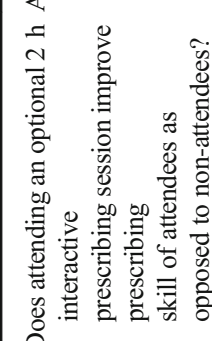

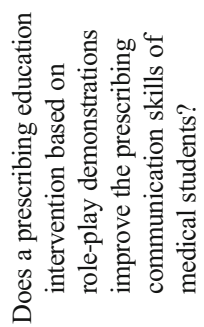

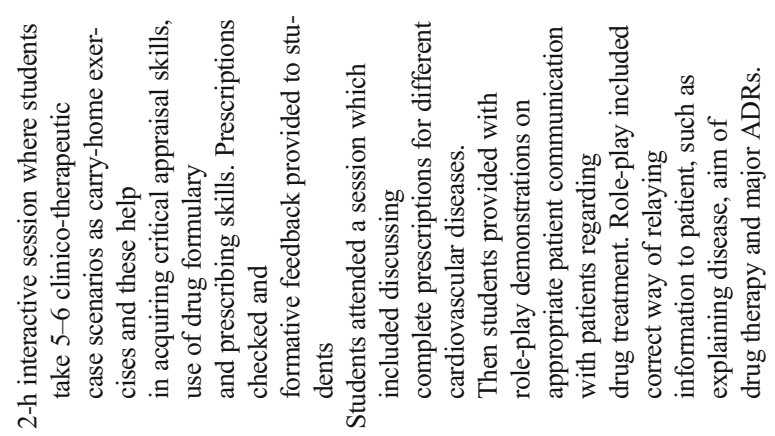

s.

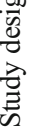

卷安过

总总言

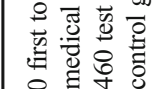

음

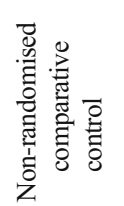

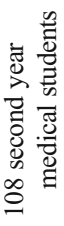

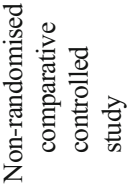

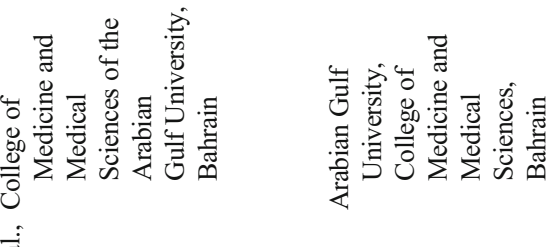

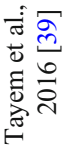




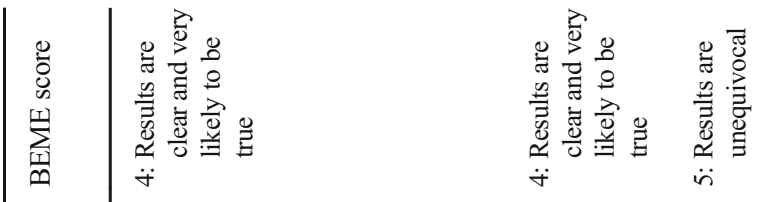

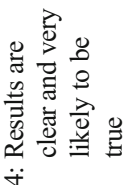

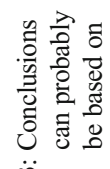

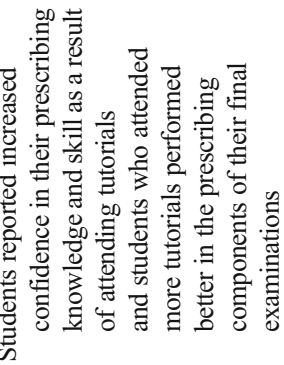

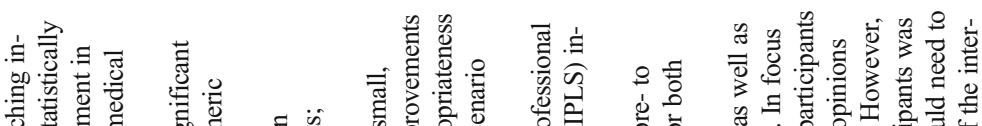

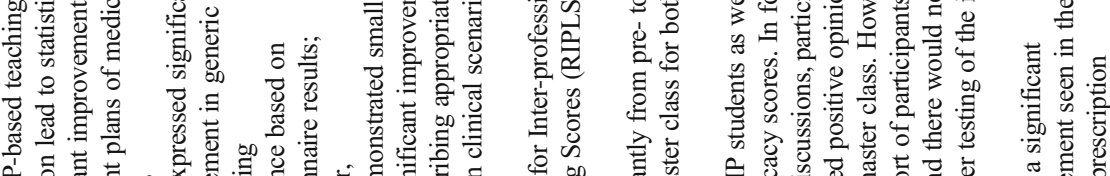

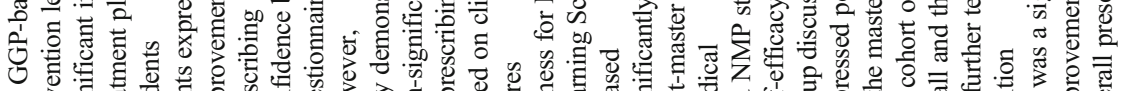

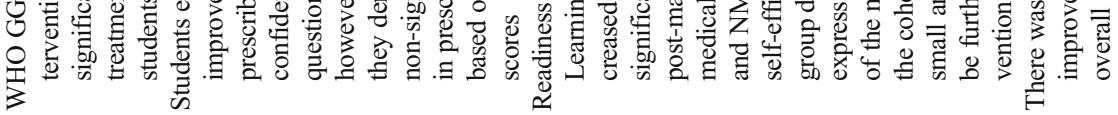
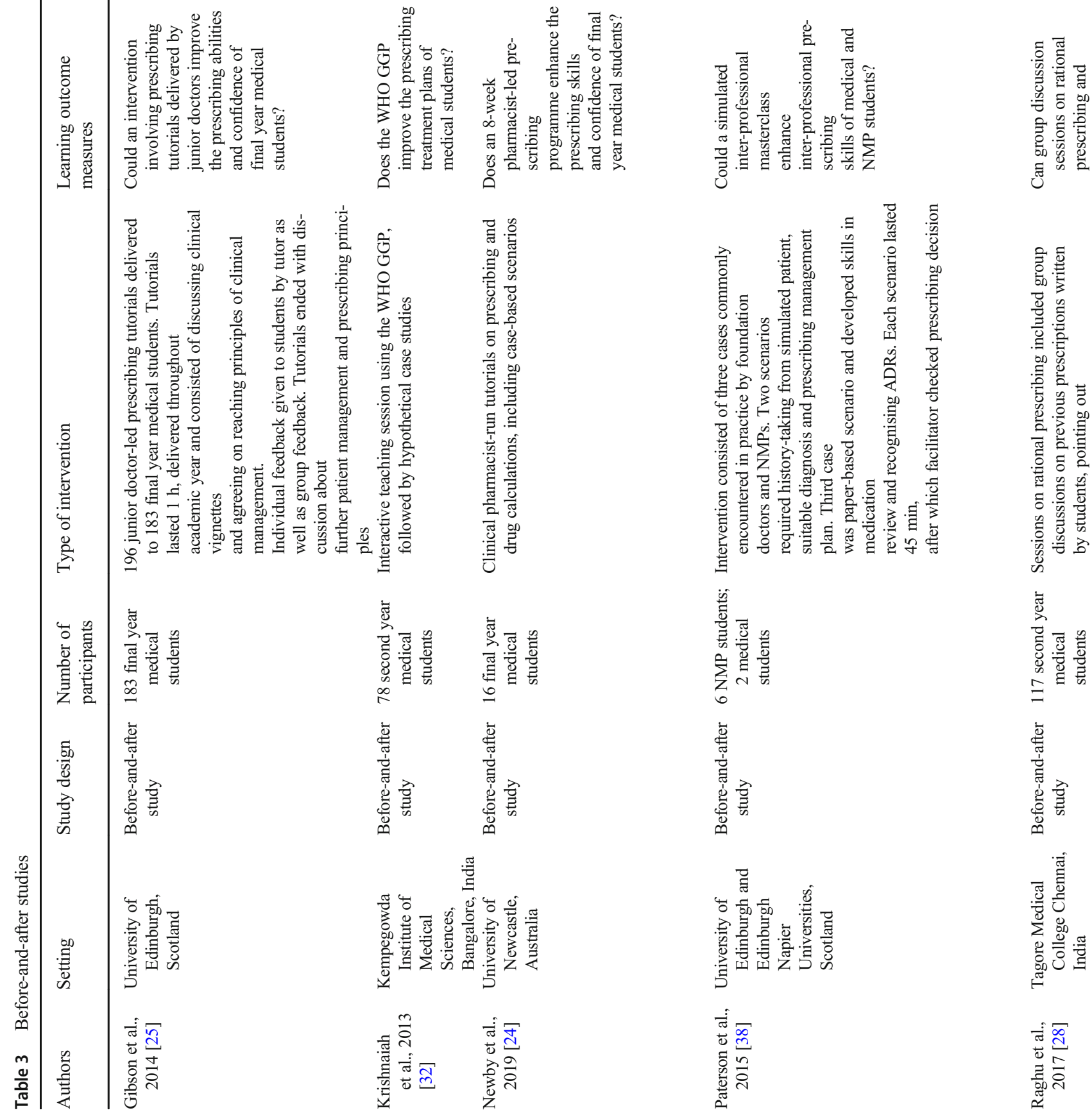

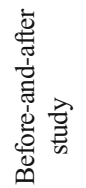
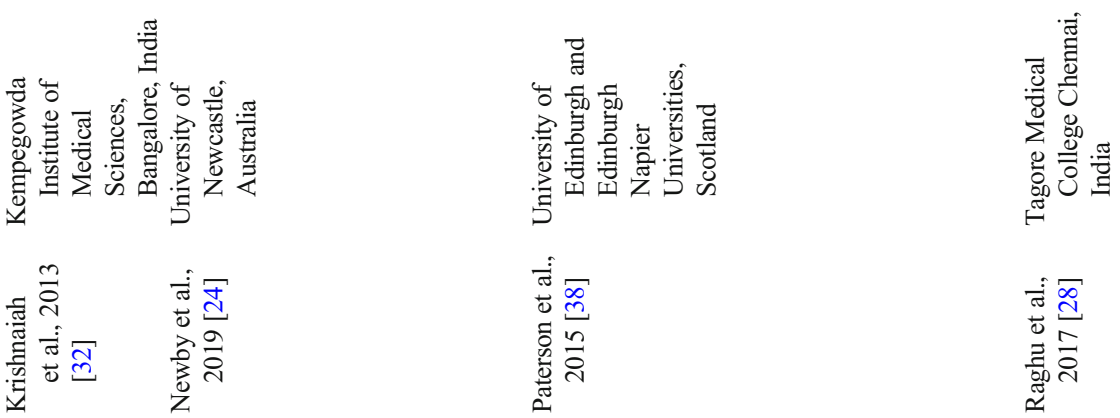

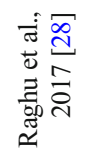




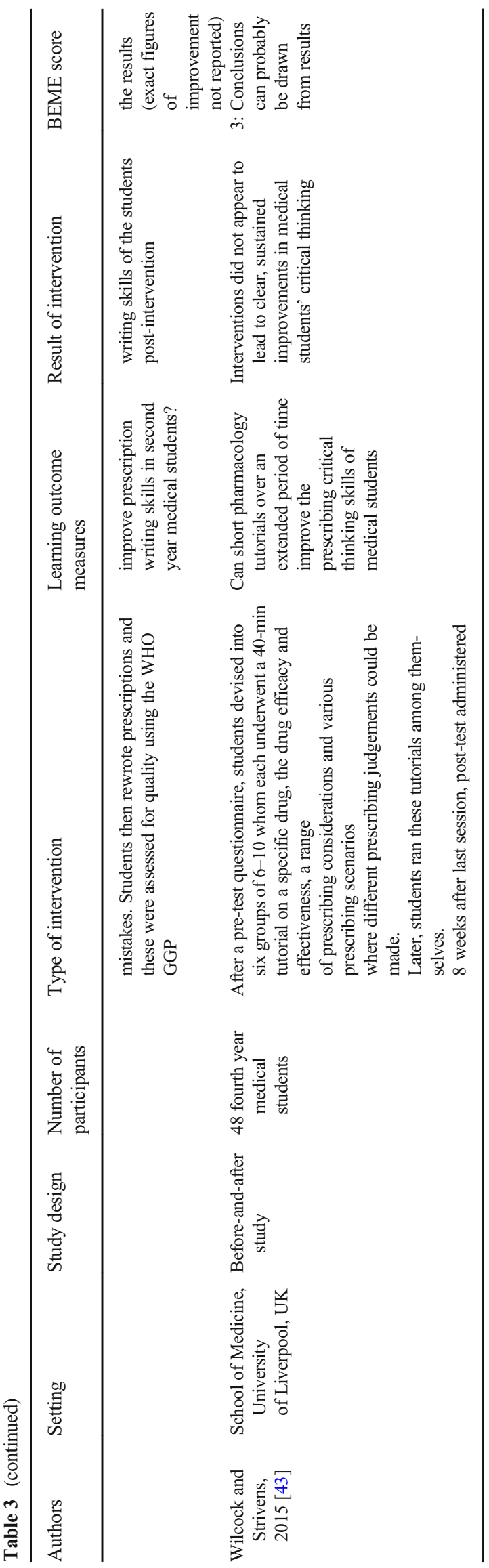

\section{Self-Directed and Online Learning}

Three studies involved interventions which included a component of self-directed or online learning [34-36]. Two studies incorporated their self-directed components of the intervention alongside PBL-based tutorials involving case-based scenarios $[34,35]$ and one study implemented an entirely individualised e-learning prescribing module [36].

Al Khaja and Sequiera [34] investigated the impact of an optional 2-h interactive prescribing skills session at the end of each pre-clerkship unit phase, where five to six clinical scenarios were discussed. Hauser et al. [35] required students enrolled in their study to collaborate with tutors to develop model patient-prescriber conversation guides. Following a PBL session on medication non-adherence where they defined learning goals, students conducted independent research on strategies to achieve their learning goals in anticipation of a second PBL session where they discussed results of their research findings, which was followed by the workshop where they devised their conversation guides. Sikkens et al. [36] designed a randomised controlled intervention where a group of fourth-year medical students were provided access to a 6week e-learning module with eight clinical cases based on the WHO GGP.

The outcomes of these studies were assessed through observation of usual course assessment, where the scores of participants were higher as compared to those who had not been recruited for the study [34]; student reflections in the programme portfolio, where students expressed a high level of satisfaction with the intervention [35]; and through MCQ knowledge tests and OSCE simulations, where it was found that students exposed to the e-learning group performed significantly better and pass rates were much higher compared to the control group. Survey results also showed that students rated the e-learning module to have enhanced their prescribing confidence in antimicrobial therapy [36].

\section{Simulation and Role-play}

Three studies implemented an educational intervention centred around learning through role-play and SimulationBased Medical Education (SBME) [37-39]. Two studies implemented a mixed disciplinary small-group approach to their role-play method of teaching $[37,38]$ and one study used a large-group experimental observation approach [39].

Cooke et al. [37] split medical and pharmacy students into small mixed-disciplinary groups who consulted with simulated patients and subsequently devised a working diagnosis, a mock prescription and detailed management plan to explain to the simulated patient. Paterson et al. [38] collaborated medical and non-medical prescribing students into multidisciplinary groups where they would devise prescriptions for three scenarios, two with simulated patients and one paper based. 


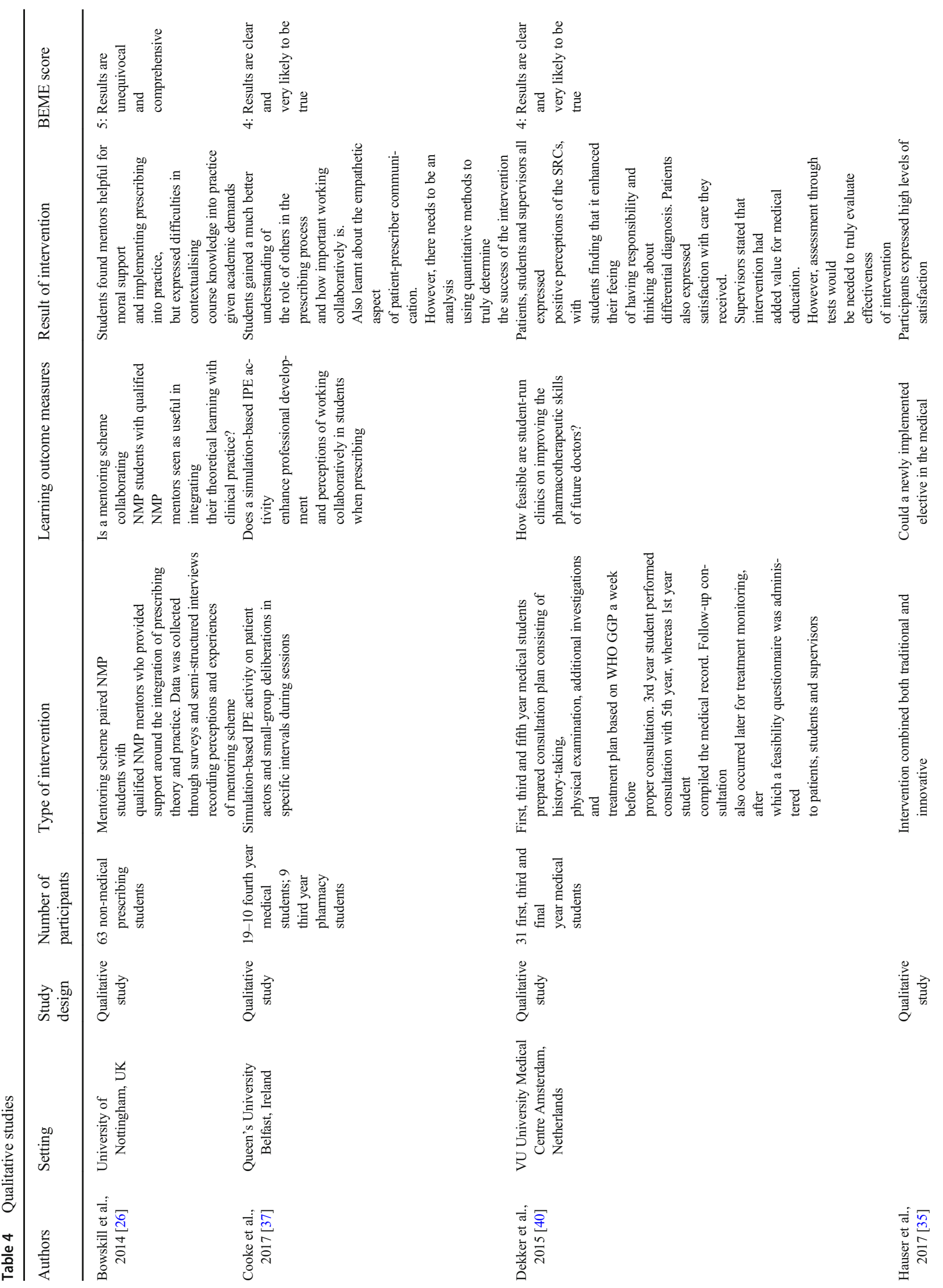




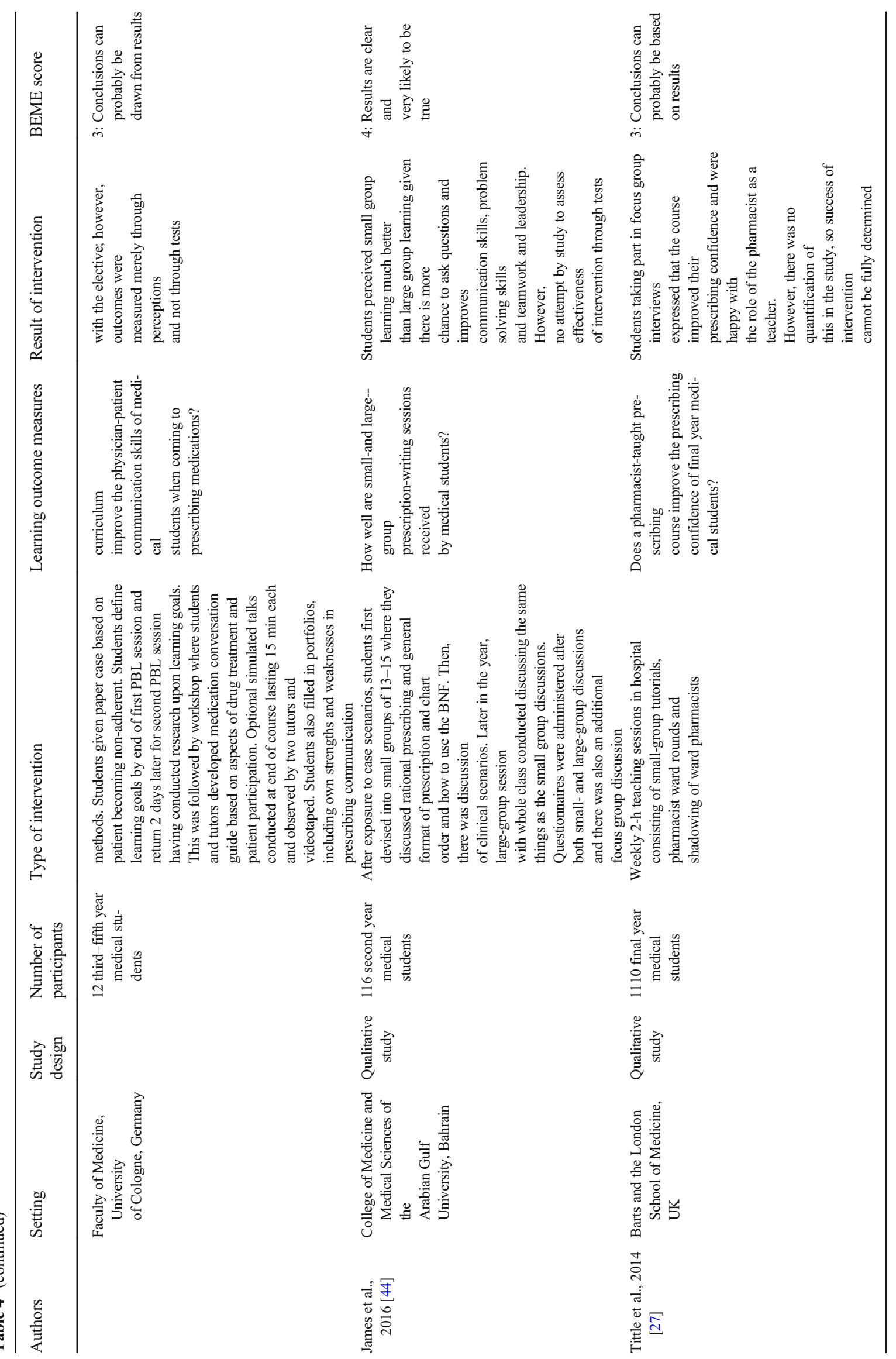


Tayem et al.'s [39] large-group demonstration intervention used a student volunteer on patient communication with regard to drug treatment. The faculty member acted as the physician and the volunteer student acted as the patient. All students had opportunity to act as volunteers in these demonstrations.

Study outcomes were assessed through both qualitative and quantitative approaches. Cooke et al.'s [37] focus group participants expressed positive perceptions of the intervention in focus groups, stating the ability to apply theory into practice in a safe environment along with understanding the role of other healthcare professionals in prescribing. Paterson et al.'s [38] focus group discussions indicated that students positively received the master classes, praised the concept of working in small groups and gained a greater awareness and appreciation of the roles of other professionals in prescribing. They also used a pre- and post-readiness for interprofessional learning score (RIPLS) and self-efficacy score to evaluate the impact of the interprofessional simulation exercise. Tayem et al.'s [39] used recorded questionnaires, where students found the role-play demonstrations instructive, helping to enhance their ability to communicate drug therapy information effectively to patients, increase prescription-writing confidence and that they would like to be given further opportunities to undertake role-playing exercises in other facets of their medical education. Additionally, students attending focus groups reported that the educational intervention helped develop interaction skills with patients and that the exercise would be most effective within small groups. Moreover, OSCE scores of those attending these role-play sessions were higher than those of nonattendees.

\section{Peer-Based and Inter-Professional Learning}

Two studies implemented educational interventions where either students from multiple stages of the medical programme were recruited for team-based learning or students from different degree programmes were brought together to partake in an inter-professional-based learning experience [40, 41]. One study implemented a small-group experiential learning approach under supervision [40] and one study used a blended approach of didactic lectures and case-based small-group learning [41].

Dekker et al. [40] recruited first-, third- and fifth-year medical students to take part in a pilot intervention involving student-run clinics (SRCs), where first-, thirdand fifth-year medical students were tasked with collaborating in consultations with real patients with a supervisor overseeing the consultation. Like Dekker et al., Achike et al. [41] also conducted a pilot study.
However, this intervention brought together both second-year medical and fourth-year nursing students for an inter-professional learning (IPL) class. The class consisted of a brief didactic lecture followed by a smallgroup discussion on a clinical scenario and group presentation. Outcomes were measured by Dekker et al. [40] through evaluation questionnaires by students, supervisors and patients, from which feedback was positive all-round, with the consensus that the SRC was safe, provided high level of care and was beneficial to the students [40]. Likewise, Achike et al. (2014) [41] administered feedback questionnaires to students before they left the class, which showed overall positive perceptions of the class, with students complementing interactions with students of other professions and learning more about the process of rational drug choice.

Two studies implemented peer-based learning between students of the same cohort [42, 43]. Both studies implemented small-group teaching; however, one of these also incorporated large-group discussions at the end of the session [42] and the other implemented specific tutorials on a single topic [43].

Zgheib et al.'s study [42] included six clinical pharmacology sessions which were delivered twice monthly over a period of 3 months, of which five were team-based learning (TBL) sessions including activities such as compiling of group prescriptions and group formularies, small-group work on MCQs eventually being joined into whole-class discussion on answers, group work on clinical scenarios and their appropriate prescribing decisions. Wilcock and Strivens [43] conducted a study where a certain segment of the overall prescribing education intervention involved teaching between peers. Groups of six to ten students received one 40-min tutorial every 2 weeks on the medications aspirin, tiotropium and simvastatin. During the 6 weeks of these tutorials, one student in each group was asked to voluntarily provide their own tutorial to their peers on a fourth medication of their choice while following the same tutorial format.

The interventions were evaluated through multiple approaches. Zgheib et al. [42] graded group prescriptions, formularies and answers to case scenarios compiled in the sessions and provided students with the opportunity to mention the strengths and weaknesses of the course through completing course evaluation forms. The scores of the group prescriptions, formularies and case scenarios improved after each session and students expressed satisfaction with the format of the sessions, mentioning that they helped with improving their group interaction skills. Wilcock and Strivens [43] administered post-tests to their students, who demonstrated struggles on the ethics of prescribing and, although enjoyed delivering tutorials to their peers, did not appear to display sustained improvements in their critical thinking [43]. 


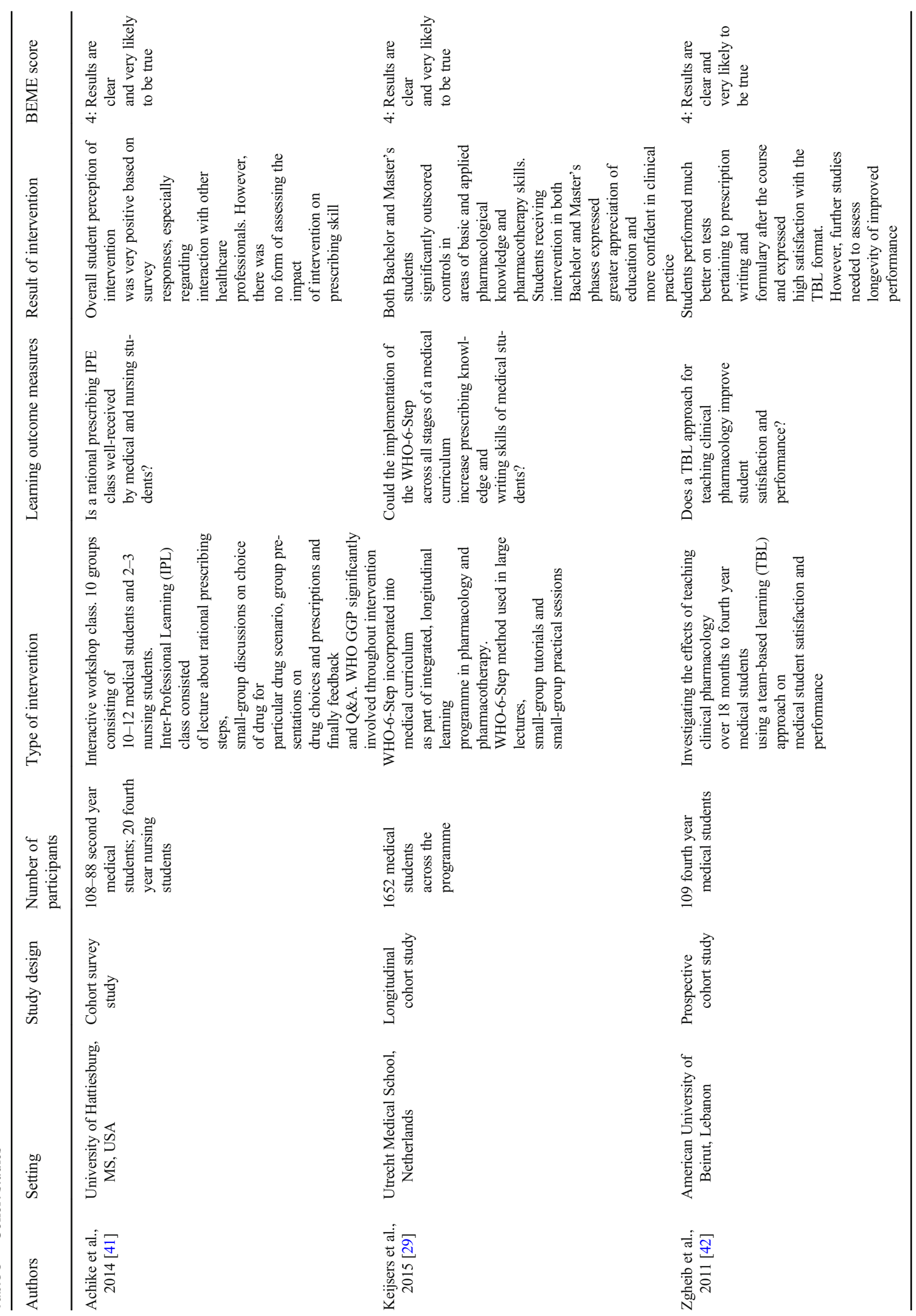




\section{Other Studies}

Two studies did not fit under any specific theme as their objectives were of a more general nature [44, 45]. One study investigated whether case-based teaching was more effective in small-group or large-group settings. Small groups were made up of 13 to 15 students each and the large-group session included the entire cohort. Both sessions concluded with the distribution of questionnaires to students regarding their perceptions of the session. Focus group discussions also took place where a small number of students were asked to express their views and perspectives on both the small-group and large-group approaches. The results of both questionnaires and focus groups indicated a strong preference by students for the small-group teaching sessions [44].

Celebi et al. [45] conducted a study investigating whether a module on drug-related problems (DRPs) could help reduce the number of prescribing errors. Group 1 underwent the week-long prescription training course followed by a week-long skills laboratory training period, while group 2 acted as the late intervention group by undergoing the week-long skills laboratory training before the prescription training course. Both groups underwent assessments before the training, a week later and at the end of the training programme. The training module included a 90-min seminar on adverse drug reactions (ADRs), prescribing errors and special needs patients. Another $90 \mathrm{~min}$ was dedicated to practical training based on a virtual case of congestive heart failure. The next 3 days involved the students practicing prescriptions for real-life patients every morning and discussing the real-life patient cases with lecturers in afternoon sessions, affording attention towards avoiding prescribing errors. At the end of the week, students were required to sit an examination with cases like assessment cases but with different diseases. The results of the assessments demonstrated a significant decrease in prescription errors. These results were more prominent in the early intervention group [45].

\section{Discussion}

In the last 10 years, we found 22 studies which met the inclusion criteria of educational interventions aimed at improving the prescribing skills and competencies of medical and non-medical prescribing students. These showed that a considerable amount of studies continue to be conducted on the best educational approaches to improving prescribing skills; however, as reported by previous systematic reviews [17, 18], generalisability and validity continue to be limited due to the diversity and heterogeneity of the reported studies.

The most recent literature review on this topic was conducted by Kamarudin et al. [16], which reported that many interventions were designed based on the concepts of the WHO GGP. This review also found that prescribing education interventions continue to be designed using the main concepts of the WHO GGP, demonstrating that despite its publication being back in 1994, the guideline continues to be the leading model for safe and rational prescribing to this day. This assertion is aided by the positive results yielded by interventions designed around the WHO GGP, both in assessment and student perception [28-33].

Despite there being a range of different educational interventions to improve the teaching of prescribing, most of these interventions feature the heavy use of clinical case scenarios. Brauer et al. [46] report that clinical case scenarios are vital to problem-based learning in healthcare and to the development of clinical practice guidelines. This also applies to the WHO GGP, which consists of a plethora of case scenarios of various clinical areas such as diabetes, cancers and gastrointestinal, respiratory and cardiovascular disorders. Hence, the designing of effective prescribing educational interventions requires the inclusion of robust clinical scenarios as they can be applied to improving multiple aspects of prescribing competencies such as prescription-writing, prescribing communication and recognising of ADRs. In addition, apart from one study, all studies reported a high level of success regarding their interventions, whether through students attaining higher scores in traditional assessments, scored treatment plans and OSCEs in comparison to control groups or through students expressing positive views of the educational intervention.

Another theme to emerge from this review was the use of small-group teaching. Many of the interventions required multiple small groups of students to be created to deliver the teaching, with one study specifically evaluating the difference in effectiveness between smalland large-group teaching. Along with demonstrating high scores in assessments, small-group teaching was particularly perceived positively in qualitative interviews with students. NMP programmes consist of far less student numbers per cohort as compared to medical school programmes; however, studies introducing educational interventions to NMP programmes remain very low, as this review could only locate two studies involving NMP programmes, one introducing a mentoring scheme to NMP students and the other involving an IPL intervention with medical students. Given that certain areas of the literature indicate an incredibly low prescribing error rate of NMPs [12], the specific benefits of small- 
group teaching in the context of prescribing skill require further investigation.

Despite identifying a range of different educational interventions aimed at improving prescribing education, the level of innovation seen in these interventions appears to be low, given that most studies used orthodox teaching methods such as didactic lectures and group exercises throughout. In a literature review, Dearnley et al. [47] categorised innovation in medical education to include simulation; digital teaching aids; online/elearning teaching and assessment; social media and virtual learning environments. Only three studies implemented a degree of innovation, where simulated and real-life patients and role-play were used. Here, although one of the studies failed to provide an insight into the content of the simulated consultations, when students were provided with the opportunity to use their prescribing skills on either simulated or real-life patients, their responses were overwhelmingly positive. Some of the studies mentioned the use of self-directed learning aided through an online e-learning system; however, it was unclear what content was included in these e-learning systems. None of the studies implemented the use of social media or innovative uses of virtual learning environments such as virtual reality with virtual patients. Most studies implemented interventions which, for the most part, were based on case scenarios on paper.

Although with the exception of one study, all interventions were reported to be successful in improving the prescribing skill and competency of students and were perceived positively, questions on their long-term effects upon prescribing practice of students beyond graduation and into their full-time clinical careers still remain as these studies failed to implement a longitudinal follow-up of whether their benefits on the prescribing practice of these students are sustained over a long period of time, as this would be a more reliable indicator of whether an educational intervention has achieved its desired outcome. Moreover, studies which only assessed the benefits of an intervention through the views and perspectives of the students undertaking them would be greatly enhanced if they utilised assessments and evaluated whether the scores of these assessments supported the positive viewpoints of the students.

Given that most studies only assess the short-term impact of educational interventions on prescribing practice, educators should also assess whether the positive impact of these interventions is sustained over a longer period as prescribers advance in their careers. Also, the WHO GGP continues to be a model from which prescribing educators design their teaching approaches. This could partly be due to it providing a comprehensive prescribing guidance on many areas of expertise using clinical case scenarios, something established as being core to problem-based learning. Given the lack of educational interventions being evaluated in NMP programmes, it would be prudent to design an intervention around the WHO GGP and evaluate its effectiveness in an NMP setting due to the existence of a variety of clinical areas of expertise in NMP programme cohorts.

This review did include certain limitations. As we limited the inclusion criteria to include studies involving students only, we could have included studies involving junior doctors. The search strategy also excluded nonEnglish language papers. In addition, given that the papers we identified reported positive outcomes and perspectives as a result of the interventions, there is also the possibility of positive publication bias.

Overall, this review was able to retrieve a broad range of studies investigating various prescribing education interventions.

\section{Conclusion}

Although a wide range of educational interventions to improve prescribing skills and competencies have been developed, despite their high success rate in the short term in both assessment and student perception, there still exists a lack of innovation in these interventions. Given that we are seeing other areas of medical education adapting their teaching approaches to be more innovative with the recent rise in technology, prescribing curricula also need to adapt and evaluate the scope of implementing educational approaches which utilise innovations such as virtual reality and explore areas where students can commit errors in a safe environment and learn from these to better their prescribing skills in preparation for real-life clinical practice.

Data Availability Not applicable

\section{Compliance with Ethical Standards}

Conflict of Interest The authors declare that they have no conflict of interest.

Ethics Approval Not applicable

Consent to Participate Not applicable

Consent for Publication Not applicable

Code Availability Not applicable 


\section{Appendix}

\section{Identification of potential relevant studies and titles screened $(n=1,137)$}

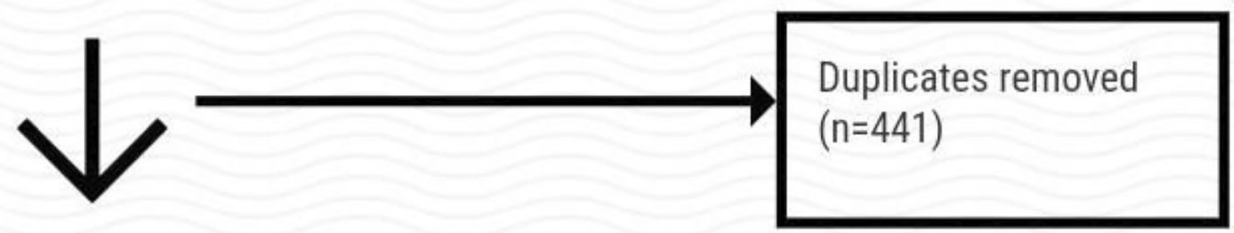

\section{Titles and abstracts} screened $(n=696)$

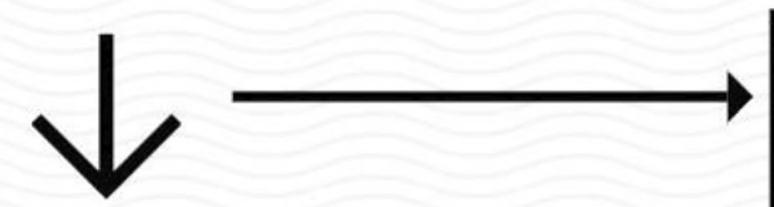

Papers Excluded because: not

relevant to prescribing, no inclusion of medical/NMP students, study conducted before $2009(n=638)$
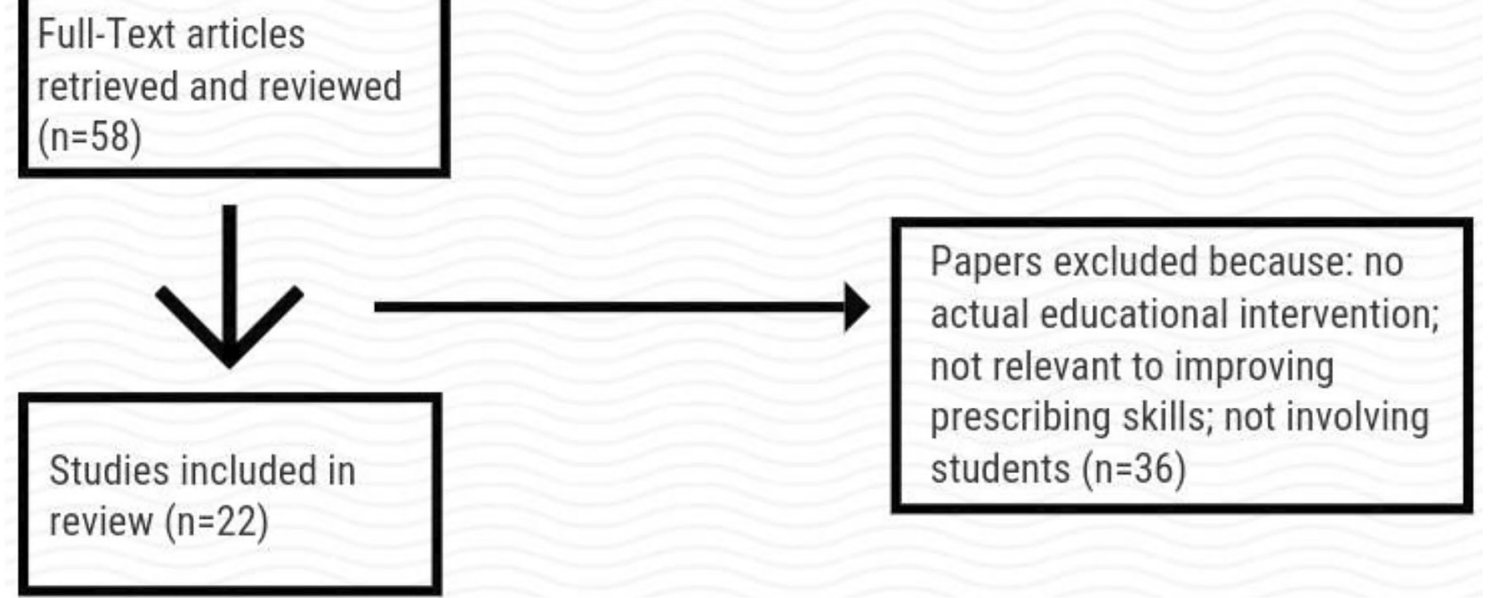

Fig. 1 Flowchart of rapid review

Open Access This article is licensed under a Creative Commons Attribution 4.0 International License, which permits use, sharing, adaptation, distribution and reproduction in any medium or format, as long as you give appropriate credit to the original author(s) and the source, provide a link to the Creative Commons licence, and indicate if changes were made. The images or other third party material in this article are included in the article's Creative Commons licence, unless indicated otherwise in a credit line to the material. If material is not included in the article's Creative Commons licence and your intended use is not permitted by statutory regulation or exceeds the permitted use, you will need to obtain permission directly from the copyright holder. To view a copy of this licence, visit http://creativecommons.org/licenses/by/4.0/.

\section{References}

1. Dornan T, Ashcroft D, Heathfield H, Lewis P, Miles J, Taylor D, et al. An in-depth investigation into causes of prescribing errors by foundation trainees in relation to their medical education: EQUIP study. London: General Medical Council; 2009. p. 1-215.

2. Dean B, Barber N, Schachter M. What is a prescribing error? Qual Health Care. 2000;9:232-7.

3. Tully MP, Ashcroft DM, Dornan T, Lewis PJ, Taylor D, Wass V. The causes of and factors associated with prescribing errors in hospital inpatients: a systematic review. Drug Saf. 2009;32(10):819-36. 
4. Velo GP, Minuz P. Medication errors: prescribing faults and prescription errors. Br J Clin Pharmacol. 2009;67(6):624-8.

5. Sayers YM, Armstrong P, Hanley K. Prescribing errors in general practice: a prospective study. Eur J Gen Pract. 2009;15(2):81-3.

6. Bobb A, Gleason K, Husch M, Feinglass J, Yarnold PR, Noskin GA. The epidemiology of prescribing errors: the potential impact of computerized prescriber order entry. Arch Intern Med. 2004;164(7):785-92.

7. Ashcroft DM, Lewis PJ, Tully MP, Farragher TM, Taylor D, Wass $\mathrm{V}$, et al. Prevalence, nature, severity and risk factors for prescribing errors in hospital inpatients: prospective study in 20 UK hospitals. Drug Saf. 2015;38(9):833-43.

8. Cope LC, Abuzour AS, Tully MP. Nonmedical prescribing: where are we now? Ther Adv Drug Safet. 2016;7(4):165-72.

9. Weiss MC. Diagnostic decision making: the last refuge for general practitioners? Soc Sci Med. 2011;73(3):375-82.

10. Watterson A, Turner F, Coull A, Murray I (2009) An evaluation of the expansion of nurse prescribing in Scotland Document prepared on behalf of Scottish Government Social Research. ;Available from: https://dspace.stir.ac.uk/bitstream/1893/2109/1/ 0087056[1].pdf. Accessed 15 April 2020

11. Latter S, Smith A, Blenkinsopp A, Nicholls P, Little P, Chapman S. Are nurse and pharmacist independent prescribers making clinically appropriate prescribing decisions? An analysis of consultations. J Health Serv Res Policy. 2012;17(3):149-56.

12. Baqir W, Crehan O, Murray R, Campbell D, Copeland R. Pharmacist prescribing within a UK NHS hospital trust: nature and extent of prescribing, and prevalence of errors. Eur J Hosp Pharm. 2015;22(2):79-82.

13. Aronson JK. A prescription for better prescribing. Br J Clin Pharmacol. 2006;61:487-91.

14. Nazar H, Nazar M, Rothwell C, Portlock J, Chaytor A, Husband A. Teaching safe prescribing to medical students: perspectives in the UK. Adv Med Educ Pract. 2015;6:279-95. https://doi.org/10.2147/ AMEP.S56179.

15. Tobaiqy M, McLay J, Ross S. Foundation year 1 doctors and clinical pharmacology and therapeutics teaching. A retrospective view in light of experience. Br J Clin Pharmacol. 2007;64(3):363-72.

16. Kamarudin G, Penm J, Chaar B, Moles R. Educational interventions to improve prescribing competency: a systematic review. BMJ Open. 2013;3(8):e003291.

17. Ostini R, Hegney D, Jackson C, Williamson M, Mackson JM, Gurman K, et al. Systematic review of interventions to improve prescribing. Ann Pharmacother. 2009;43(3):502-13.

18. Brennan N, Mattick K. A systematic review of educational interventions to change behaviour of prescribers in hospital settings, with a particular emphasis on new prescribers. Br J Clin Pharmacol. 2013;75(2):359-72.

19. Tricco AC, Langlois EV, Straus SE, editors. Rapid reviews to strengthen health policy and systems: a practical guide. Geneva: World Health Organization; 2017.

20. Popay J, Roberts H, Sowden A, Petticrew M, Arai L, Rodgers M, Britten N, Roen K, Duffy S (2006) Guidance on the conduct of narrative synthesis in systematic reviews. A product from the ESRC methods programme Version;1:b92.

21. Moher D, Liberati A, Tetzlaff J, Altman DG. Prisma Group. Preferred reporting items for systematic reviews and meta-analyses: the PRISMA statement. PLoS Med. 2009;6(7):e1000097.

22. Waffenschmidt S, Knelangen M, Sieben W, Bühn S, Pieper D. Single screening versus conventional double screening for study selection in systematic reviews: a methodological systematic review. BMC Med Res Methodol. 2019;19(1):132.

23. BEME About BEME. [cited July 26, 2012]; Available at: http:// www2.warwick.ac.uk/fac/med/beme/about/. Accessed 20 Feb 2020.
24. Newby DA, Stokes B, Smith AJ. A pilot study of a pharmacist-led prescribing program for final-year medical students. BMC Med Educ. 2019;19(1):54.

25. Gibson KR, Qureshi ZU, Ross MT, Maxwell SR. Junior doctor-led 'near-peer' prescribing education for medical students. Br J Clin Pharmacol. 2014;77(1):122-9.

26. Bowskill D, Meade O, Lymn JS. Use and evaluation of a mentoring scheme to promote integration of non-medical prescribing in a clinical context. BMC Med Educ. 2014;14(1):177.

27. Tittle V, Randall D, Maheswaran V, Webb A, Quantrill S, Roberts M. Practical prescribing course: a student evaluation. Clin Teach. 2014;11(1):38-42.

28. Raghu G, Arumugam B, Paul P. Evaluation of hands on training on prescription writing skills among medical students in a tertiary care teaching hospital. Natl J Physiol Pharm Pharmacol. 2017;7(12): 1371-6.

29. Keijsers CJ, Segers WS, De Wildt DJ, Brouwers JR, Keijsers L, Jansen PA. Implementation of the WHO-6-step method in the medical curriculum to improve pharmacology knowledge and pharmacotherapy skills. Br J Clin Pharmacol. 2015;79(6):896-906.

30. Thenrajan P, Murugan PR. Impact of patient-based teaching in improving prescription writing skills of II MBBS students. Int J Appl Basic Med Res. 2016;6(3):174-7.

31. Kamat SK, Marathe PA, Patel TC, Shetty YC, Rege NN. Introduction of case based teaching to impart rational pharmacotherapy skills in undergraduate medical students. Indian $\mathrm{J}$ Pharmacol. 2012;44(5):634-8.

32. Krishnaiah V, Ramaiah V, Ramakrishna R. Comparison of rational pharmacotherapy approach by medical students with and without Guide to Good prescribing guidelines. Natl J Physiol Pharm Pharmacol. 2013;3(1):53.

33. Tichelaar J, Uil den SH, Antonini NF, van Agtmael MA, de Vries TP, Richir MC. A 'SMART' way to determine treatment goals in pharmacotherapy education. Br J Clin Pharmacol 2016;82(1):280-284.

34. Al Khaja KA, James H, Sequeira RP. Effectiveness of an educational intervention on prescription writing skill of preclerkship medical students in a problem-based learning curriculum. J Clin Pharmacol. 2013;53(5):483-90.

35. Hauser K, Koerfer A, Niehaus M, Albus C, Herzig S, Matthes J (2017) The prescription talk-an approach to teach patient-physician conversation about drug prescription to medical students. GMS J Med Educ 34(2)

36. Sikkens JJ, Caris MG, Schutte T, Kramer MH, Tichelaar J, van Agtmael MA. Improving antibiotic prescribing skills in medical students: the effect of e-learning after 6 months. J Antimicrob Chemother. 2018;73(8):2243-6.

37. Cooke C, Gormley GJ, Haughey S, Barry J. Tracing the prescription journey: a qualitative evaluation of an interprofessional simulation-based learning activity. Adv Simul. 2017;2(1):14.

38. Paterson R, Rolfe A, Coll A, Kinnear M. Inter-professional prescribing masterclass for medical students and non-medical prescribing students (nurses and pharmacists): a pilot study. Scott Med J. 2015;60(4):202-7.

39. Tayem YI, Altabtabaei AS, Mohamed MW, Arrfedi MM, Aljawder HS, Aldebous FA, et al. Competence of medical students in communicating drug therapy: value of role-play demonstrations. Indian J Pharmacol. 2016;48(1):37-41.

40. Dekker RS, Schutte T, Tichelaar J, Thijs A, van Agtmael MA, de Vries TP, et al. A novel approach to teaching pharmacotherapeutics - feasibility of the learner-centered studentrun clinic. Eur J Clin Pharmacol. 2015;71(11):1381-7.

41. Achike FI, Smith J, Leonard S, Williams J, Browning F, Glisson J. Advancing safe drug use through interprofessional learning (IPL): a pilot study. J Clin Pharmacol. 2014;54(7):832-9.

42. Zgheib NK, Simaan JA, Sabra R. Using team-based learning to teach clinical pharmacology in medical school: student satisfaction 
and improved performance. J Clin Pharmacol. 2011;51(7):110111.

43. Wilcock J, Strivens J. A study to enhance medical students' professional decision-making, using teaching interventions on common medications. Med Educ Online. 2015;20(1):27097.

44. James H, Tayem YI, Al Khaja KA, Veeramuthu S, Sequeira RP. Prescription writing in small groups as a clinical pharmacology educational intervention: perceptions of preclerkship medical students. J Clin Pharmacol. 2016;56(8):1028-34.

45. Celebi N, Weyrich P, Riessen R, Kirchhoff K, LammerdingKöppel M. Problem-based training for medical students reduces common prescription errors: a randomised controlled trial. Med Educ. 2009;43(10):1010-8.

46. Brauer PM, Hanning RM, Arocha JF, Royall D, Goy R, Grant A, et al. Creating case scenarios or vignettes using factorial study design methods. J Adv Nurs. 2009;65(9):1937-45.

47. Dearnley C, McClelland GT, Irving D. Innovation in teaching and learning in health higher education. London: The Higher Education Academy; 2013.

Publisher's Note Springer Nature remains neutral with regard to jurisdictional claims in published maps and institutional affiliations. 